\title{
Glioma cancer stem cells secrete Gremlin1 to promote their maintenance within the tumor hierarchy
}

\author{
Kenneth Yan, ${ }^{1,2,3}$ Qiulian Wu, ${ }^{1}$ Diana H. Yan, ${ }^{2}$ Christine H. Lee, ${ }^{1,4}$ Nasiha Rahim, ${ }^{1}$ Isabel Tritschler, ${ }^{1,5}$ \\ Jennifer DeVecchio, ${ }^{1}$ Matthew F. Kalady, ${ }^{1}$ Anita B. Hjelmeland, ${ }^{1}$ and Jeremy N. Rich ${ }^{1,6}$ \\ ${ }^{1}$ Department of Stem Cell Biology and Regenerative Medicine, Lerner Research Institute, Cleveland Clinic, Cleveland, Ohio \\ 44195, USA; ${ }^{2}$ Case Western Reserve University School of Medicine, Cleveland, Ohio 44195, USA; ${ }^{3}$ Department of Cell Biology, \\ Case Western Reserve University, Cleveland, Ohio 44195, USA; ${ }^{4}$ Department of Pharmacology, Case Western Reserve \\ University, Cleveland, Ohio 44195, USA; ${ }^{5}$ Department of Neurology, University Hospital Zurich, Zurich 8091, Switzerland
}

\begin{abstract}
Glioblastomas are the most prevalent and lethal primary brain tumor and are comprised of hierarchies with selfrenewing cancer stem cells (CSCs) at the apex. Like neural stem cells (NSCs), CSCs reside in functional niches that provide essential cues to maintain the cellular hierarchy. Bone morphogenetic proteins (BMPs) instruct NSCs to adopt an astrocyte fate and are proposed as anti-CSC therapies to induce differentiation, but, paradoxically, tumors express high levels of BMPs. Here we demonstrate that the BMP antagonist Gremlin1 is specifically expressed by CSCs as protection from endogenous BMPs. Gremlin1 colocalizes with CSCs in vitro and in vivo. Furthermore, Gremlin1 blocks prodifferentiation effects of BMPs, and overexpression of Gremlin1 in non-CSCs decreases their endogenous BMP signaling to promote stem-like features. Consequently, Gremlin1-overexpressing cells display increased growth and tumor formation abilities. Targeting Gremlin1 in CSCs results in impaired growth and self-renewal. Transcriptional profiling demonstrated that Gremlin1 effects were associated with inhibition of $\mathbf{p} 21^{\text {WAF1/CIP1 }}$, a key CSC signaling node. This study establishes CSC-derived Gremlin1 as a driving force in maintaining glioblastoma tumor proliferation and glioblastoma hierarchies through the modulation of endogenous prodifferentiation signals.
\end{abstract}

[Keywords: stem cell hierarchies; bone morphogenetic proteins (BMPs); BMP antagonists; Gremlin1; cancer stem cells; glioblastoma]

Supplemental material is available for this article.

Received December 1, 2013; revised version accepted April 4, 2014.

Stem cell proliferation is tightly constrained by niches that provide maintenance cues and prevent uncontrolled growth. Upon exiting its niche, a stem cell undergoes loss of self-renewal and lineage specification, thereby linking the microenvironment with the normal cellular hierarchy. Many cancers display similar hierarchies, with stem-like neoplastic cells or cancer stem cells (CSCs) that maintain tumors and give rise to differentiated progeny (Reya et al. 2001). Like their nontransformed relatives, CSCs reside in defined niches but are capable of actively modifying their microenvironment (Bao et al. 2006b; Cheng et al. 2013).

Glioblastoma, World Health Organization grade IV astrocytoma, is a deadly primary brain tumor typically presenting in patients over the age of 40 . The prognosis for glioblastoma is dismal, as tumors inevitably recur

${ }^{6}$ Corresponding author

E-mail richj@ccf.org

Article published online ahead of print. Article and publication date are online at http://www.genesdev.org/cgi/doi/10.1101/gad.235515.113. despite multimodal therapy, with a median overall survival of $<11$ mo in population-based studies and 15 mo for patients treated in clinical trials (Weller et al. 2013). Among solid cancers, glioblastomas have demonstrated one of the most reliable models of cellular hierarchies, with CSCs at the top of the hierarchy and more differentiated progeny (nonstem glioma cells) below (Singh et al. 2004). CSCs share a number of properties with normal neural stem cells (NSCs), such as the expression of stem cell markers (Sox2, Olig2, and Nestin) and differentiation potential, albeit often with aberrant patterns ( $\mathrm{Li}$ et al. 2009). However, they are distinct from their normal brethren, as they harbor genetic abnormalities and form

(C) 2014 Yan et al. This article is distributed exclusively by Cold Spring Harbor Laboratory Press for the first six months after the full-issue publication date (see http://genesdev.cshlp.org/site/misc/terms.xhtml). After six months, it is available under a Creative Commons License (Attribution-NonCommercial 4.0 International), as described at http:// creativecommons.org/licenses/by-nc/4.0/. 
tumors in vivo. Furthermore, they contribute to tumor spread (Cheng et al. 2011a), angiogenesis (Bao et al. 2006b), immune evasion (Yi et al. 2011; Ye et al. 2012), and therapeutic resistance (Bao et al. 2006a), providing a rationale to target CSCs and their supporting niche for therapeutic benefit.

CSCs are functionally defined by their capacity to selfrenew and propagate tumors that phenocopy the parental tumor (Reya et al. 2001), while non-CSCs are unable to propagate tumors in the same time frame. We and others have shown that CSCs are resistant to current treatment modalities of radiation and chemotherapy (Bao et al. 2006a; Liu et al. 2006; Chen et al. 2012b). Together, these two properties of tumor formation ability and therapeutic resistance suggest that CSCs might contribute to tumor recurrence and, ultimately, the death of the patient. Therefore, there have been multiple endeavors to uncover therapies to selectively target the CSC population. A number of potential therapeutic targets have arisen in recent years that are expressed by CSCs. These include TGFß (Ikushima et al. 2009; Penuelas et al. 2009; Anido et al. 2010; Tchaicha et al. 2011; Eichhorn et al. 2012), MELK (Gu et al. 2013; Joshi et al. 2013), iNOS (Eyler et al. 2011), Ephrins (Binda et al. 2012; Day et al. 2013), transcription factors such as Ascll (Rheinbay et al. 2013) and Myc (Wang et al. 2008; Zheng et al. 2008), and epigenetic modifiers such as MLL (Gallo et al. 2013), among others. Differentiation therapy offers an alternative approach that has been used in hematopoietic cancers with success (Ades et al. 2010). However, similar approaches in brain tumors with retinoids and deacetylase inhibitors have had limited efficacy to date (Grauer et al. 2011; Friday et al. 2012).

To improve on differentiation-based therapies, it is notable that despite the growth advantages of CSCs in vivo, tumors derived from CSCs rapidly recreate hierarchies, with CSCs often representing a minor fraction of the neoplastic compartment. These observations are challenging to reconcile with cell-autonomous evolutionary models of cancer growth, which suggest that clones with selective growth advantages will dominate the tumor bulk, but the competitive advantages of molecular pathways are dependent on the host environment. Differentiated cell populations are not strictly responsible for tumor propagation, but these cells may serve as components of the microenvironment to maintain the CSCs, suggesting a potential drive toward continuous creation of a hierarchy. In brain tumors, differentiated tumor cells secrete cytokines such as interleukin-6 (Wang et al. 2009) and extracellular matrix (laminins) (Lathia et al. 2012) that stimulate CSC survival and tumor growth. A similar relationship is found in the normal colon, where Lgr5-positive crypt cells act as a highly proliferative stem cell pool in direct proximity with CD $24^{+}$Paneth cell progeny that provide ligands for stem cell proliferation (Sato et al. 2011).

Collectively, these observations suggest that the differentiated progeny of CSCs are not "waste" cells, as has been hypothesized, but rather are an essential component of tumors. Therefore, there are likely to be effectors that maintain both CSC and non-CSC components of the tumor hierarchy. Consequently, an inefficient differentiation therapy will be ineffective against the tumor, as these driving forces will oppose such therapies to reequilibrate the balance of CSCs and non-CSCs. Targeting these driving forces that maintain tumor hierarchies will offer nodes of fragility that should synergize with current differentiation therapies for therapeutic benefit.

Bone morphogenetic proteins (BMPs)—particularly BMP2, BMP4, and BMP7-have been proposed as potential differentiation therapies against glioblastoma that drive astrocytic specification of glioblastoma CSCs (Piccirillo et al. 2006; Lee et al. 2008; Chirasani et al. 2010). BMPs represent a group of $\sim 20$ structurally related cytokines within the TGF- $\beta$ superfamily of cysteine knot proteins (Varga and Wrana 2005; Sieber et al. 2009; Rider and Mulloy 2010). They exist as homodimers and heterodimers and bind to heteromeric complexes composed of type 1 and type 2 BMP receptors. Canonical BMP signaling involves the phosphorylation of receptor-regulated Smad proteins (R-Smads)-Smad1, Smad5 and Smad8-by the type 1 BMP receptor. Phosphorylation of R-Smads causes a conformational change that leads to their interaction with Smad4 (co-Smad). The activated Smad complex then translocates into the nucleus to activate transcriptional targets. BMP signaling is modulated tightly in tissue- and developmental stage-specific manners through several different mechanisms, including receptor expression and affinity as well as the presence of extracellular or intracellular antagonists (Sieber et al. 2009; Rider and Mulloy 2010; Walsh et al. 2010).

In a number of reports, BMPs have been demonstrated to drive astrocytic differentiation in CSCs, as measured by the induction of the astrocyte marker GFAP (Piccirillo et al. 2006; Lee et al. 2008; Chirasani et al. 2010; Gargiulo et al. 2013). Consequently, BMP-treated CSCs have a decreased proliferation rate and tumor formation in a xenograft mouse model (Piccirillo et al. 2006) as well as a decreased invasive potential in rat glioma (Zhang et al. 2002). Recent work has shown that the tumor-repressive role of BMPs can be modulated through the transcriptional factor Atf3 (Gargiulo et al. 2013). BMPs also cause differentiation in colon cancer and osteosarcoma (Lombardo et al. 2011; Wang et al. 2011). However, a paradox arises, as a number of groups have demonstrated elevated BMP expression, particularly BMP2, within human gliomas (Liu et al. 2009; Zhang et al. 2009). Furthermore, endogenous NSCs, which demonstrate tropism toward gliomas (Aboody et al. 2000; Lesniak 2006), offer an additional source of BMP7 (Chirasani et al. 2010). Thus, high levels of BMP ligands are present in gliomas despite their apparent negative impact on CSCs. It is hard to rationalize BMPs as a part of the CSC microenvironment, as unchecked BMP signaling throughout gliomas, as suggested by these data, would theoretically cause rampant differentiation, effectively collapsing the glioma hierarchy.

Here, we resolve this apparent contradiction by investigating the regulation of BMP signaling within human gliomas. Our data show that although BMP ligands are secreted by both CSCs and nonstem glioma cells, 
BMP downstream signaling is more active in the nonstem glioma cells. This apparent difference in downstream signaling can be explained by the secretion of the BMP antagonist Gremlin1 by the CSC population. Exogenous Gremlin1 production in nonstem glioma cells promotes CSC-like properties, and targeting Gremlin1 in CSCs impairs their growth. Gremlin1-mediated increases in CSC proliferation can be explained by Gremlin1-mediated down-regulation of the cyclin-dependent kinase (CDK) inhibitor (CKI) p21 $1^{\mathrm{WAF} 1 / \mathrm{CIP} 1}$. Through this mechanism, we establish Gremlin1 as a key player in promoting CSC self-renewal and maintaining the glioma hierarchy in the context of endogenous differentiation signals. Regulation of the BMP-Gremlin 1 axis appears to be essential for the tumor hierarchy. Thus, inhibition of Gremlin1 will synergize well with a BMP-based differentiation therapy for glioblastoma treatment.

\section{Results}

BMP signaling is attenuated in CSCs compared with nonstem glioma cells

BMPs have been reported to be highly expressed by human gliomas (Liu et al. 2009; Zhang et al. 2009) despite their causing astrocytic differentiation of CSCs and subsequently decreasing their proliferation rates. These data are corroborated by BMP expression in patient tumors in the Repository for Molecular Brain Neoplasia Data (REMBRANDT) data set (Supplemental Fig. S1). To resolve this apparent paradox, we first determined BMP signaling in different tumor subpopulations.

We isolated functionally validated matched CSC and nonstem glioma cell populations from primary patient specimens and xenografts using the CSC marker CD133. While CD133 has been controversial as a CSC marker because it has not been universally informative across all tumors and is not likely exclusively expressed by CSCs, in most models tested, we found that acute use of CD133 from an in vivo environment can segregate CSCs and non-CSCs. As validation, we interrogated models to be used in this study for the utility of CD133. CD133positive populations represented $<5 \%$ of the cells in our specimens (Supplemental Fig. S2A). CD133-positive populations expressed stem cell markers (Supplemental Fig. S2B-E) and had an increased ability for self-renewal (Supplemental Fig. S2F-K) and tumor formation in immunocompromised mice (Supplemental Fig. S2L,M), supporting CD133 as informative of CSC phenotypes in these models. As a measurement for endogenous BMP pathway activation, we quantified levels of phosphorylated/activated Smad1, Smad5, and Smad8 proteins, the direct downstream mediators of canonical BMP signaling, within matched CSCs and non-CSCs. Smad phosphorylation and consequent BMP signaling were higher in all nonstem glioma cells tested compared with matched CSCs (Fig. 1A). This observation suggests that while BMP signaling is present in gliomas as a whole, the CSC subpopulation possesses a mechanism to inhibit BMP signaling and prevent differentiation.
To investigate the mechanism by which CSCs selectively limit BMP signaling, we first determined the relative levels of pertinent BMP ligands and receptors in CSC and non-CSC fractions. While all tumors expressed $\mathrm{BMP}$ ligands, the relative expression levels of BMP2, BMP4, and BMP7 in CSCs and non-CSCs varied between specimens. Overall, there was no uniform trend in ligand expression that would result in consistent differential BMP signaling (Fig. 1B; Supplemental Fig. S3A-C). Similarly, we did not detect consistent changes in BMPR 1a or $\mathrm{BMPR} 1 \mathrm{~b}$ receptor expression across tumor specimens to explain the preferential BMP pathway activation (Fig. 1C; Supplemental Fig. S3A,D). Therefore, variations in the levels of BMP ligands or receptors cannot account for the consistent observed differences in BMP pathway activation.

\section{CSCs secrete elevated levels of the BMP antagonist Gremlin1}

In development and in cancer, the BMP pathway is regulated in a stage- and cell-specific fashion by a number of extracellular antagonists (Rider and Mulloy 2010; Walsh et al. 2010). These antagonists share a common cysteine knot protein motif with BMPs and inhibit the ligands by direct binding and prevention of ligand-receptor interaction (Groppe et al. 2002). Antagonists include Gremlin1, Noggin, Chordin, Ventroptin, and Brorin and play protumorigenic roles in a number of different cancer types (Namkoong et al. 2006; Sneddon et al. 2006; Hsu et al. 2008; Secondini et al. 2011; Gao et al. 2012; Kim et al. 2012; Mulvihill et al. 2012). In examining the mRNA expression of several BMP antagonists in CSC and nonstem glioma cell populations, we found robust expression of Gremlin1 in the CSCs, with comparatively modest or absent expression of other antagonists (Fig. 1D,E). Therefore, we further interrogated the role of Gremlin1 and found a striking elevation of Gremlin1 expression in CSCs compared with nonstem glioma cells in all samples tested (Fig. 1F). There were no consistent differences in the comparative expression of Chordin across tumor populations (Supplemental Fig. S3E). We confirmed the differences in Gremlinl protein secretion via ELISA (Fig. 1G). This observation suggested Gremlin1 production as a mechanism by which CSCs protect themselves from BMPs within the tumor.

To further confirm that Gremlin1 is secreted in a CSCspecific manner, we evaluated Gremlin1 levels both in vitro and in vivo via immunofluorescent staining of bulk tumor neurospheres in cell culture and xenografted and primary patient tumor specimens. We sought to examine Gremlin1 in the context of both stem and differentiation markers. Therefore, we costained with CSC markers Sox2, Olig2, Nestin, and CD133; oligodendrocyte precursor markers NG2 and O4; endothelial marker CD31; and differentiation markers GFAP, Map2, Tuj1, and PLP. In three xenografted tumors, a primary patient specimen (Fig. 2A,B), and cultured neurospheres (Supplemental Fig. S4), Gremlin was expressed on cells that were also positive for Sox2 and Olig2. Furthermore, in these same xenografts, Gremlin1 costained with stem markers Nestin 
Yan et al.
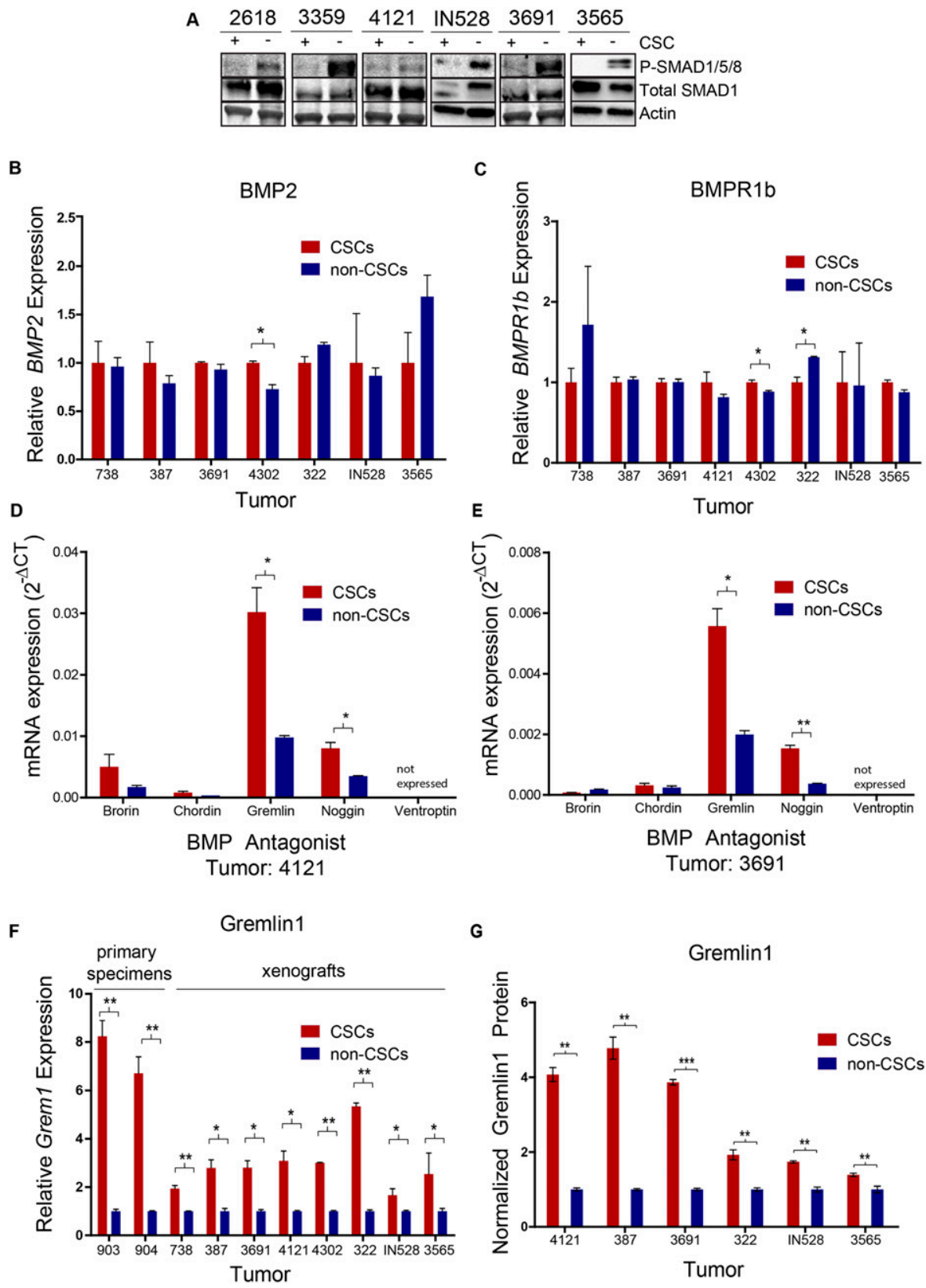

Figure 1. Glioma CSCs secrete Gremlin1 to inhibit BMP signaling. (A) Immunoblot of SMAD1/5/8 phosphorylation in matched CSC/ nonstem glioma cell populations. RT-PCR expression data of $B M P 2(B)$ and $B M P R 1 b(C)$ in matched CSC/nonstem glioma cell populations. $(D, E)$ RT-PCR expression data of a panel of BMP antagonists in CSC/nonstem glioma cell populations. (F) RT-PCR expression data of Grem1 in CSC/nonstem glioma cell populations. (G) ELISA protein expression data of Gremlin1 in matched CSC/ nonstem glioma cell populations. $\left.\left(^{\star}\right) P<0.05 ;\left(^{\star \star}\right) P<0.01 ;\left.\right|^{\star \star \star}\right) P<0.001$.

and CD133 as well as oligodendrocyte precursor markers NG2 and O4 (Fig. 2C-F). These observations suggest CSCspecific secretion of Gremlin1.

In addition, Gremlin1 staining did not colocalize with endothelial cells but was found on cells surrounding CD31positive tumor vasculature (Supplemental Fig. S5A), a wellcharacterized niche for CSCs (Calabrese et al. 2007). GFAP and Gremlin1 also had a mutually exclusive staining pattern, consistent with Gremlin1's role in limiting BMP signaling (Supplemental Fig. S5B). Gremlin1 displayed limited costaining with neuronal markers Map2 and Tuj1, suggesting a BMP-independent mechanism for neuronal differentiation (Supplemental Fig. S5C,D). Finally, the differentiated oligodendroglial marker PLP did not stain our xenograft specimens despite potent staining in normal brains (data not shown), implying the lack of a mature oligodendrocyte lineage in our tumors (Supplemental Fig. S5E).

\section{Gremlin1 antagonizes the functions of BMP in CSCs}

To validate an intact BMP signaling pathway in CSCs and that Gremlin1 could inhibit the effects of BMP 


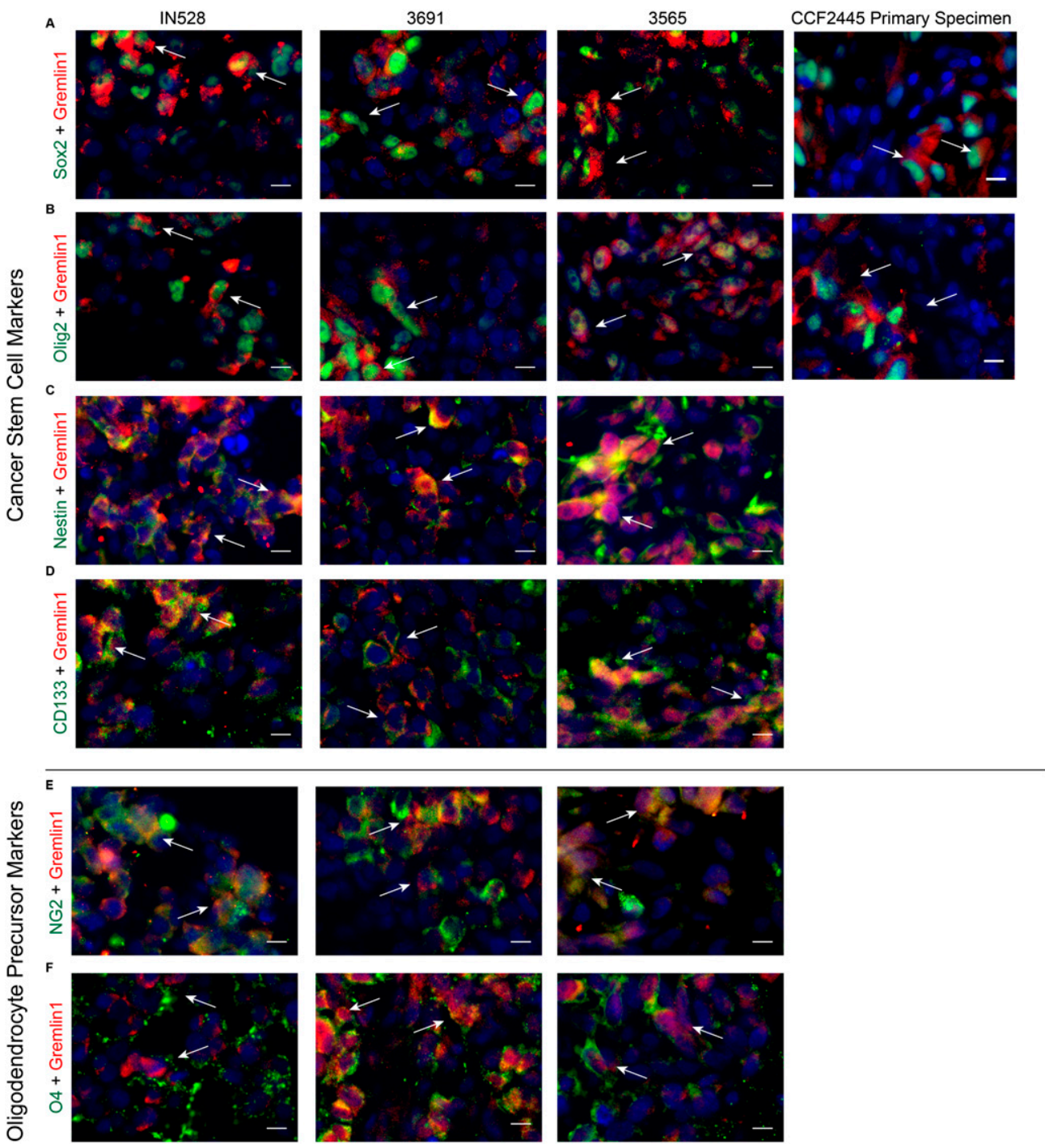

Figure 2. Gremlin 1 colocalizes with stem cell markers in glioblastoma. Immunofluorescent staining for Gremlin 1 in three patientderived xenografts and a primary human specimen with CSC markers Sox2 (A), Olig2 (B), Nestin $(C)$, and CD133 (D) and oligodendrocyte precursor markers NG2 $(E)$ and O4 $(F)$. White arrows indicate colocalization. Bar, $10 \mu \mathrm{m}$.

ligands, we treated CSCs with exogenous recombinant human BMP2 in conjunction with Gremlin1. By measuring Smad1, Smad5, and Smad8 protein phosphorylation, we found that BMP2 elicited canonical signaling in CSCs and that Gremlin1 inhibited Smad activation (Fig. 3A). Gremlin 1 was able to maintain or increase the mRNA expression of Olig2, a CSC marker, in the presence of BMP (Supplemental Fig. S6A). Furthermore, Gremlin1 blocked BMP2-mediated increases in the astrocyte marker GFAP (Supplemental Fig. S6A). A similar maintenance of the stem cell state by Gremlin 1 was confirmed at the protein level by immunofluorescent staining. BMPs decreased the protein expression of the stem cell marker Sox2 with a corresponding increase in GFAP, and Gremlin1 was able to block these effects (Supplemental Fig. S6B).

By inducing differentiation in CSCs, BMPs cause a functional decrease in CSC proliferation and tumor growth (Piccirillo et al. 2006). We therefore investigated the impact of Gremlin1 on these important CSC phenotypes. Using a cell titer assay in which ATP is a surrogate for cell proliferation, we determined that Gremlin1 was able to attenuate BMP2-mediated growth inhibition (Fig. 3B-D). Upon addition of Gremlin1, CSCs continue to proliferate even in the presence of BMP2. In addition, in in vitro limiting dilution assays, we also found that exogenous Gremlin1 blocked BMP2-mediated inhibition of neurosphere formation (Fig. 3E-M).

\section{Exogenous Gremlin1 expression promotes a stem cell phenotype}

We subsequently determined whether the addition of Gremlin1 in the absence of exogenous BMPs would promote a stem cell-like phenotype in our cells. As CSCs express high levels of Gremlin1, we transduced non-CSCs 

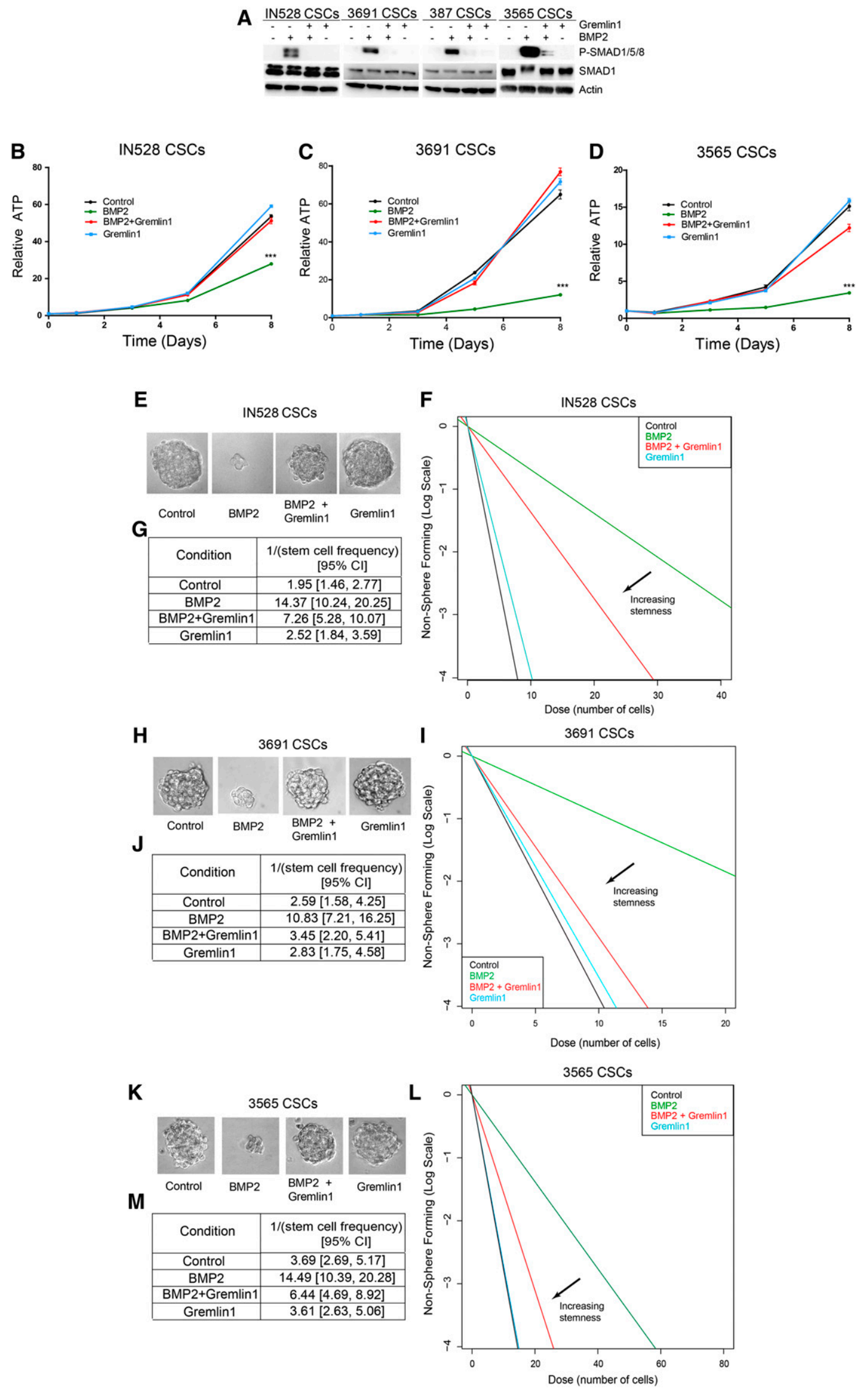

Figure 3. Exogenous Gremlin1 can block BMP2-mediated growth inhibition and depletion of self-renewal. (A) Immunoblot of phosphorylated and total Smad proteins following $30 \mathrm{~min}$ of BMP2 and/or Gremlin1 treatments. (B-D) Growth curves following BMP2 and/or Gremlin 1 treatments. $(E, H, K)$ Representative images of neurospheres in IN528, 3691, and 3565 CSCs following $10 \mathrm{~d}$ of BMP2 and/or Gremlin1 treatments. In vitro limiting dilution assays $(F, I, L)$ and quantification $(G, J, M)$ following $10 \mathrm{~d}$ of BMP2 and/or Gremlin1 treatments. $\left(^{\star \star \star}\right) P<0.001$. 
with lentiviruses expressing either Gremlin1 or a GFP control under a CMV promoter. We validated Gremlin1 overexpression by immunoblot and RT-PCR (Fig. 4A,B). As expected, Gremlin 1 overexpression diminished endogenous BMP signaling in these cells, measured by phosphorylated Smad1/5/8 expression, indicating the Gremlin1 was functional. Next, we examined differentiation and stem cell marker expression by RT-PCR and immunofluorescent staining (Fig. 4C-H). Consistent with inhibition of endogenous BMP-mediated astrocyte differentiation, Gremlin1-overexpressing cells exhibited increased expression of stem markers Sox2 and Olig2 (Fig. 4C,D) and decreased expression of astrocyte markers GFAP and S10OB (Fig. 4E,F). In an examination of immunofluorescent staining, Gremlinl overexpression also decreased GFAP and increased Sox2 expression (Fig. $4 \mathrm{G}, \mathrm{H})$. Gremlin1 overexpression did not alter the expression of neuronal (Map2 and Tuj1) or oligodendrocyte (GalC) differentiation markers (Supplemental Fig. S7).

Consistent with a less differentiated phenotype, cells transduced with Gremlin1 exhibited increased cell proliferation. We quantified this increase using CellTiter-Glo assays (Fig. 5A-C). We also noted that several tumors lost contact inhibition and formed spheroidal colonies (data not shown). When plated in an in vitro limiting dilution assay, Gremlin1-overexpressing cells promote the formation of tumor neurospheres (Fig. 5D-I). Finally, we implanted equal numbers of GFP and Gremlin1-overexpressing cells into immunocompromised mice. The addition of Gremlin1 was able to decrease tumor latency in a bulk tumor population (Fig. 5J) and increase tumor initiation in a nonstem glioma cell-enriched population (Fig. 5K).

\section{Gremlin1 increases CSC maintenance}

To establish a functional role of endogenous Gremlin1 in CSCs, we knocked down the expression of Gremlin1 in CSCs using lentiviral-based introduction of nonoverlapping shRNAs: one in the Gremlin1 coding sequence (shGrem1_485) and the other in the 3' untranslated region (shGrem1_2456). We compared the effects of these shRNAs with a control vector expressing a nontargeting control shRNA sequence that is not expressed in the human transcriptome (NT shRNA). Successful knockdown of Gremlin1 was verified by immunoblot (Fig. 6A). Knockdown of Gremlin1 in CSCs caused an increase in GFAP expression (Supplemental Fig. S8A) and a decrease in CD133 surface marker expression (Supplemental Fig. S8B-D). In addition, knockdown of Gremlin1 caused a decrease in cell proliferation quantified over time (Fig. 6B). Last, CSCs with Gremlin1 knockdown displayed decreased sphere formation, a surrogate of self-renewal, as measured by an in vitro limiting dilution assay (Fig. 6C,D; Supplemental Fig. S9). This effect was not due to changes in cell apoptosis, as there was no significant difference in Caspase activity (Supplemental Fig. S10).

We confirmed the impact of targeting Gremlin1 expression in tumor formation latency in an intracranial xenograft model (Fig. 6E). Once the final mouse bearing a tumor derived from control CSCs developed neuro- logical signs (day 35), we sacrificed a mouse from one of the shRNA conditions. H\&E staining revealed that cells transduced with the nontargeting shRNA formed highly angiogenic tumors (Fig. 6F). In contrast, cells transduced with shRNAs against Gremlin1 demonstrated no detectable tumor formation at day 35 . Because of the lack of tumor formation at day 35 , we could not determine whether the injected cells were expressing Gremlin 1 at this stage. However, when tumors finally formed in the mice in the shRNA conditions, we found that the resulting tumors were able to circumvent the Gremlin1 shRNA and reexpress Gremlin1 (Supplemental Fig. S11). Finally, to assess whether Gremlinl is relevant in the clinical realm, we used publicly available survival and expression data from The Cancer Genome Atlas (TCGA) to correlate Gremlin1 expression with patient survival. Patients were segregated into Gremlin-high-expressing and Gremlin1-low-expressing groups based on whether Grem1 levels in each patient were higher or lower than the mean Grem1 expression in the data set. By this algorithm, 174 patients were segregated into a Gremlin1-high group, and 352 patients were segregated into a Gremlin1-low group. Plotting patient survival by Grem 1 expression, we determined that higher levels of Gremlin1 expression are correlated with a worse prognosis in patients (Supplemental Fig. S12).

\section{Gremlin1 effects are associated with p21 inhibition}

To determine potential effectors that mediate cell proliferation effects downstream from Gremlin1, we performed a whole-transcript microarray in two distinct glioblastoma CSC models, comparing effects of the nontargeting control sequence shRNA and two Gremlin1 shRNAs. Ingenuity analysis of gene expression changes between each Gremlin1 shRNA and the corresponding nontargeting shRNA revealed changes in genes consistent with BMP up-regulation (Supplemental Fig. S13) as well as a number of cell cycle-related genes (Fig. 7A). Based on the phenotypic effects detailed above, we suspected that the Gremlin1-BMP axis might be linked to cell cycle progression in CSCs. We used Ingenuity's upstream analysis tool to determine top transcription factors that might be responsible for the gene expression changes in our data. Across both shRNAs in both tumor specimens, the top transcription factor predicted by the microarray to be affected by Gremlin 1 was $\mathrm{p} 21^{\mathrm{WAF} 1 / \mathrm{CIP} 1}$ (Supplemental Table 1). Several p21-regulated genes were modified in the array in a manner consistent with p21 upregulation by the Gremlin1 shRNAs (Fig. 7B).

Cells progress to the $S$ phase of the cell cycle following an accumulation of CDK activity at the end of the $G_{1}$ phase. Cell cycle arrest is often mediated by CKIs that inhibit $\mathrm{G}_{1}$-specific CDKs. TGF $\beta$ family members, including BMPs, modulate cell cycle progression through the Cip/Kip family of CKIs, in which there are three members: p21, p27, and p57 (Besson et al. 2008). While p21 is thought to play an oncogenic role through inhibition of apoptosis, its canonical role is as a tumor suppressor that decreases proliferation (Abbas and Dutta 2009). In particular, BMPs have been shown to decrease cancer cell 


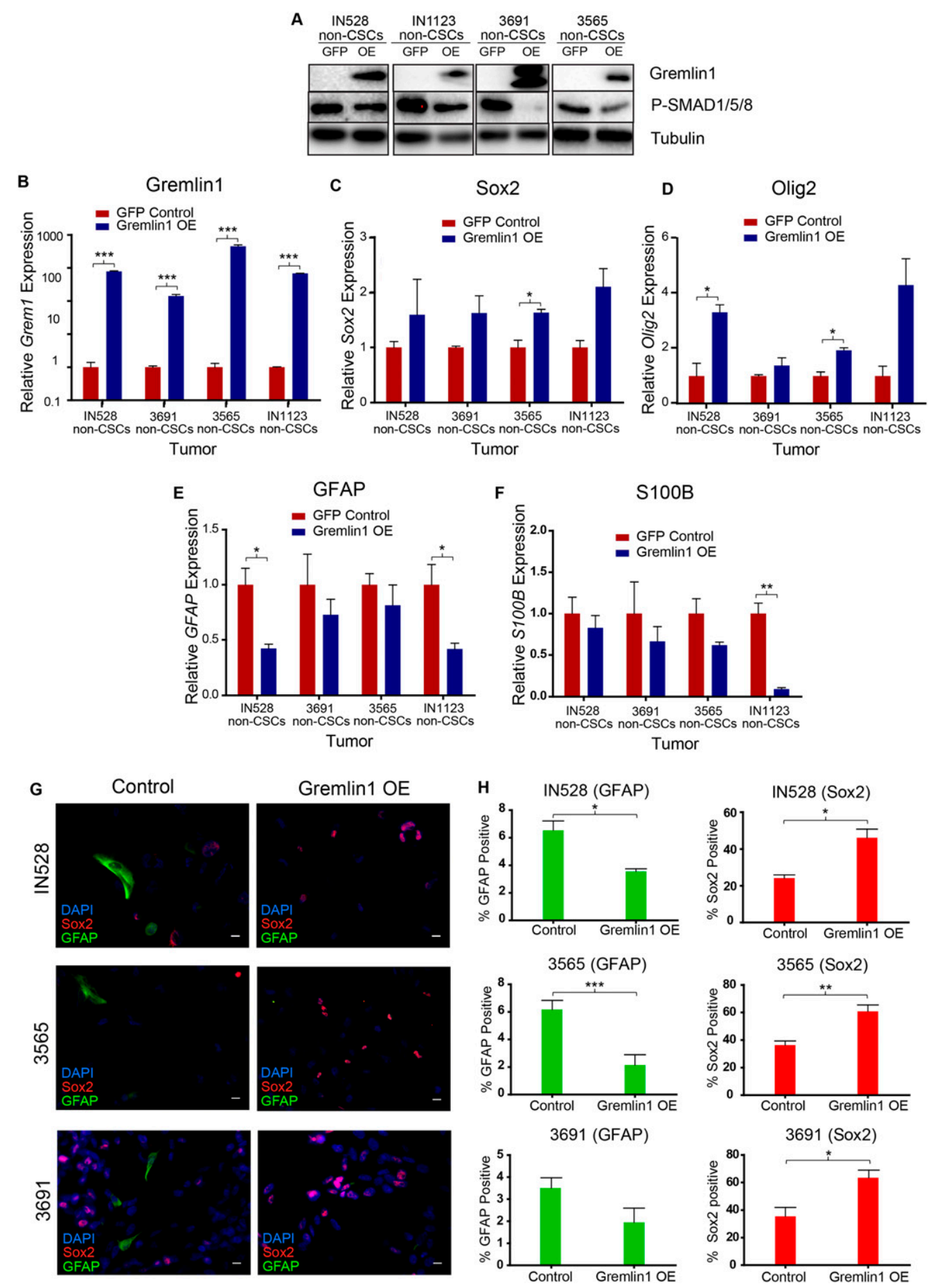

Figure 4. Gremlin 1 expression blocks endogenous BMP2 signaling and differentiation. (A) Immunoblot of Gremlin1 and P-SMAD1/5/8 in GFP versus Gremlin1-overexpressing cells in four nonstem glioma cell-enriched models. $(B-F)$ RT-PCR for Grem1 (B), Sox2 (C), Olig2 $(D)$, GFAP $(E)$, and S1OOB $(F)$ expression following Gremlin1 overexpression. $(G)$ Staining for Sox2 and GFAP following Gremlin1 overexpression. (H) Quantification of staining in $G .\left(^{\star}\right) P<0.05 ;\left(^{\star \star}\right) P<0.01 ;\left(^{\star \star \star}\right) P<0.001$. Bar, $10 \mu \mathrm{m}$.

proliferation through modulation of $\mathrm{p} 21$ levels in a number of systems, including the colon (Beck et al. 2007), breast (Chen et al. 2012a), prostate (Brubaker et al. 2004; Miyazaki et al. 2004), and thyroid (Franzen and Heldin 2001). Therefore, we hypothesized that Gremlin1 is promoting cell cycle progression in CSCs via p21 inhibition.
We confirmed that p21 is acting downstream from Gremlin1 by blotting for its expression via immunoblot following Gremlin1 overexpression and knockdown. Indeed, Gremlin1 knockdown resulted in re-expression of p21 in CSCs (Fig. 7C). Interestingly, there was little or no change in p21 RNA expression (Fig. 7B). The oncogene 
A

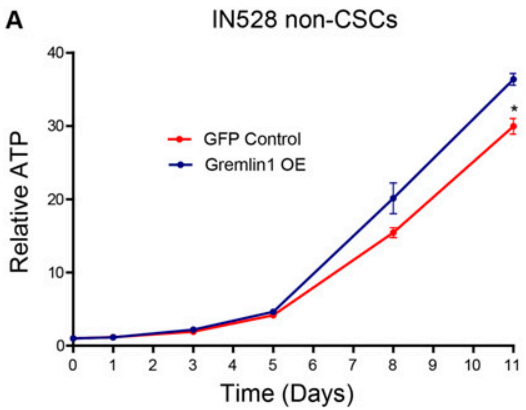

D

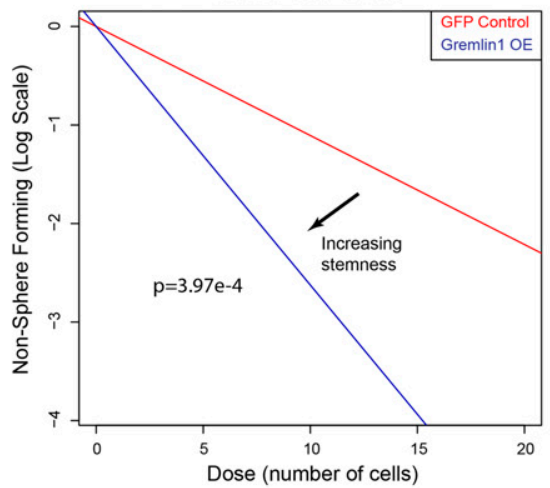

\begin{tabular}{|c|c|}
\hline Condition & $\begin{array}{c}1 /(\text { stem cell frequency) } \\
{[95 \% \mathrm{Cl}]}\end{array}$ \\
\hline GFP Control & $8.90[6.45,12.36]$ \\
\hline Gremlin1 OE & $3.81[2.78,5.34]$ \\
\hline
\end{tabular}

B

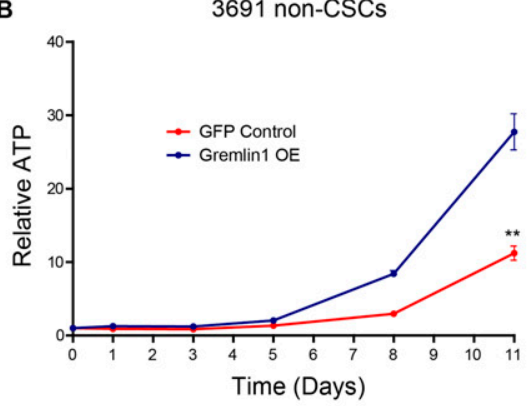

E

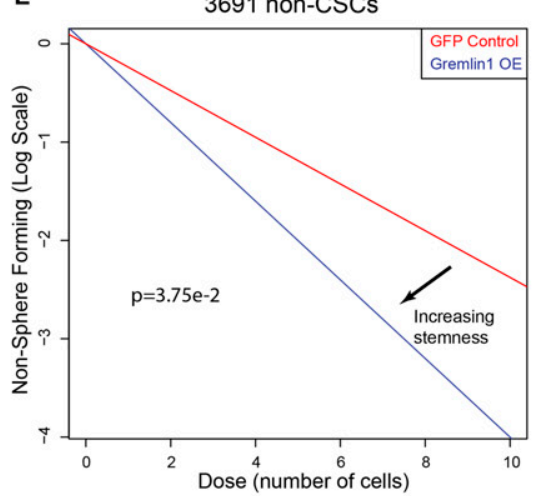

H

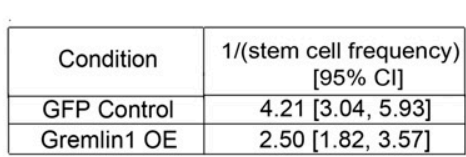

C

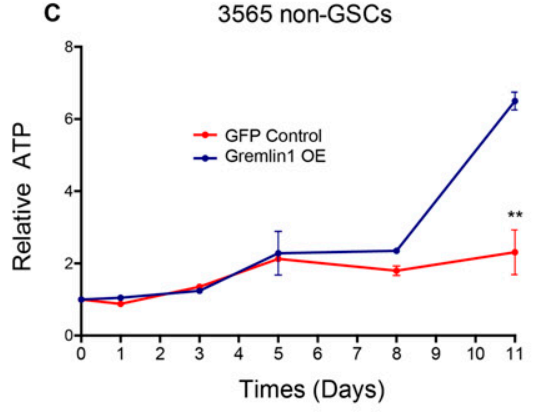

$\mathbf{F}$

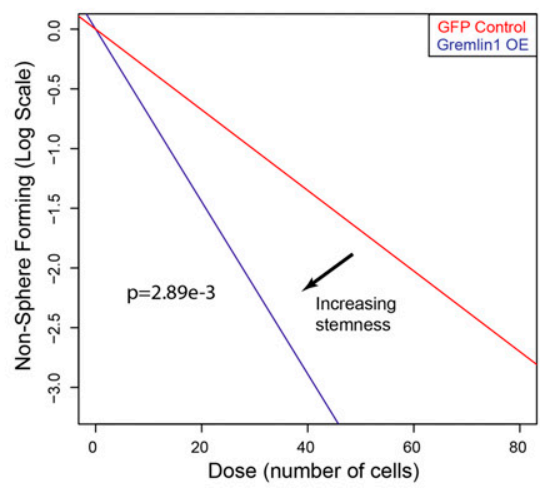

I

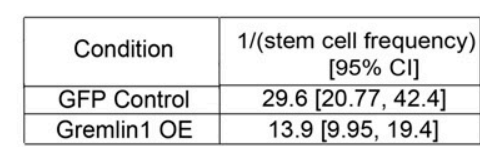

$\mathbf{J}$

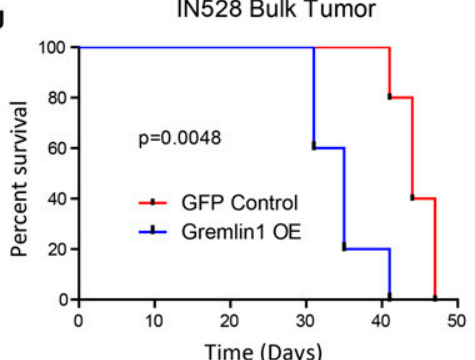

K

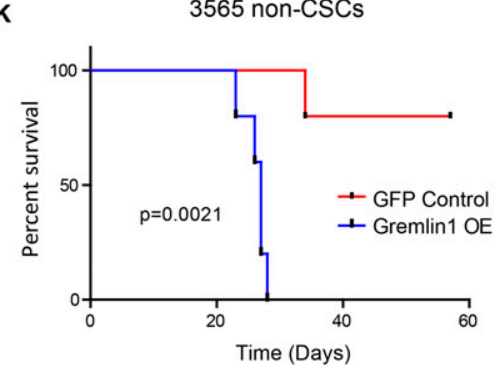

Figure 5. Gremlin1 expression promotes proliferation and tumor growth by nonstem glioma cells. $(A-C)$ Growth curves following Gremlin1 overexpression in IN528, 3691, and 3565 nonstem glioma cells. (D-F) In vitro limiting dilution assay following $10 \mathrm{~d}$ of Gremlin1 overexpression in IN528, 3691, and 3565 nonstem glioma cells. (G-I) Quantification of data in $D-F$. (J) Kaplan-Meier survival curve for immunocompromised mice injected intracranially with GFP or Gremlin1-overexpressing bulk IN528 tumor cells. $(K)$ Kaplan-Meier survival curve for immunocompromised mice injected intracranially with GFP or Gremlin1-overexpressing 3565 nonstem glioma cells. $\left(^{\star}\right) P<0.05$; $\left(^{\star \star}\right) P<0.01$.

c-myc, a reported downstream target of p21 (Vigneron et al. 2006), was inhibited by Gremlin1 knockdown. Meanwhile, levels of the related CKIs p27 and p57 were unchanged by Gremlin1 knockdown (Fig. 7C). Furthermore, Gremlin1 overexpression decreases p21 expression in nonstem glioma cell-enriched populations, with no changes in p27 and p57 (Fig. 7D). Finally, cell cycle analyses in CSCs showed that Gremlin 1 shRNAs caused a $G_{1}$ cell cycle arrest consistent with p21 activation (Fig. 7E). Therefore, our data suggest that Gremlin1 is playing a key role in suppressing p21 expression in CSCs.
Canonically, p21 is a downstream target of the tumor suppressor $\mathrm{p} 53$. Therefore, we sought to determine whether the effects of Gremlin1 on p21 are p53-dependent. As the TP53 gene is frequently mutated in glioblastoma (The Cancer Genome Atlas 2008), we performed p53 staining in our tumor specimens along with parallel sequencing of the TP53 gene. Positive p53 staining represents a mutation resulting in increased protein stability of p53 (Yemelyanova et al. 2011). In our hands, there was robust staining of p53 for one of our xenografts, IN528, and a point mutation was discovered in this tumor through sequencing (Supple- 
Yan et al.

A
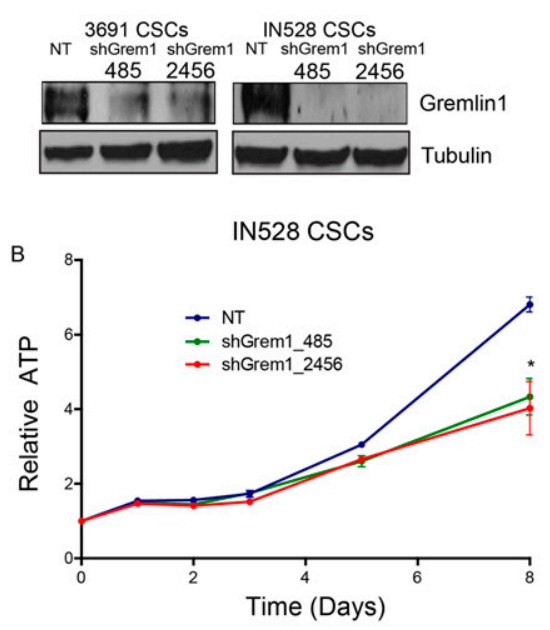

3691 CSCs



F

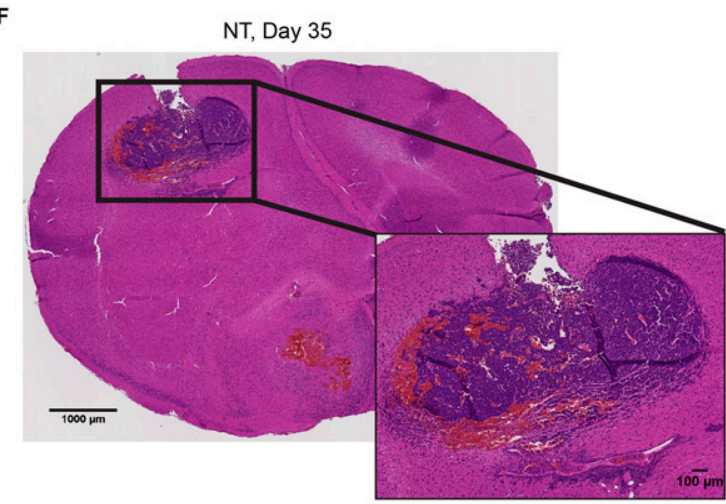

C



D

\begin{tabular}{|c|c|}
\hline Condition & $\begin{array}{c}1 /(\text { stem cell frequency) } \\
{[95 \% \mathrm{Cl}]}\end{array}$ \\
\hline NT & $2.78[2.03,3.95]$ \\
\hline shGrem1_485 & $4.65[3.39,6.47]$ \\
\hline shGrem1_2456 & $5.31[3.87,7.38]$ \\
\hline
\end{tabular}

E 3691 CSCs

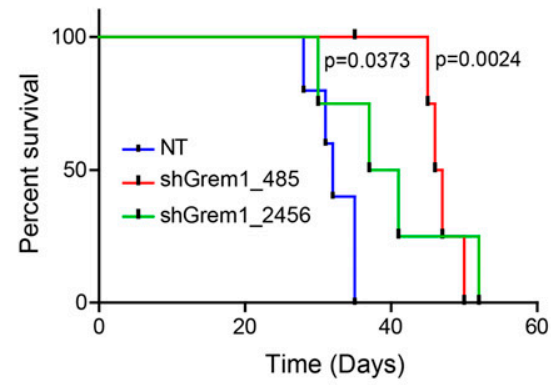

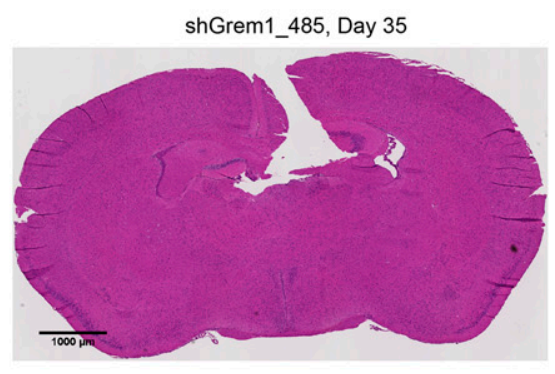

Figure 6. Gremlin1 knockdown inhibits CSC proliferation and tumor growth. $(A)$ Immunoblot of Gremlin1 following infection with a nontargeting control shRNA (NT) or shRNAs directed against Gremlin1 (485 and 2456) in two CSC models. (B) Growth curves following Gremlin1 knockdown in IN528 and 3691 CSCs. (C) In vitro limiting dilution assay following $10 \mathrm{~d}$ of Gremlin1 knockdown in IN528 CSCs. $(D)$ Quantification of data in C. $(E)$ Kaplan-Meier survival curves for immunocompromised mice injected intracranially with a vector containing a nontargeting sequence control (NT) shRNA or Gremlin1 shRNA-infected 3691 CSCs. $(F)$ H\&E staining of brains injected with 3691 CSCs expressing an NT shRNA or Gremlin1 shRNA-infected cells. $\left(^{\star}\right) P<0.05$.

mental Fig. S14A,B). In contrast, tumor models 3691 and 3565 were p53 wild type. As Gremlin1 knockdown and overexpression have similar effects in these tumors, it is likely that Gremlin1's effects on p21 are independent of p53 status.

\section{Discussion}

In glioblastoma as well as many other cancers, intratumoral heterogeneity plays a large role in therapeutic resistance.
Resistant subpopulations of cells within tumors survive traditional therapies and permit tumor regrowth. In gliomas, an increasingly recognized model to explain this heterogeneity is the existence of a cellular hierarchy with CSCs at the peak (Reya et al. 2001). CSCs are defined by their tumor propagation potential and are often resistant to conventional therapies, suggesting that they represent the resistant subpopulation responsible for 
A

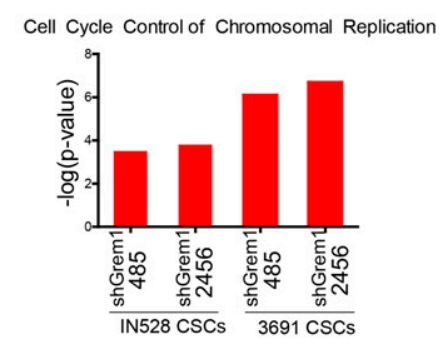

C
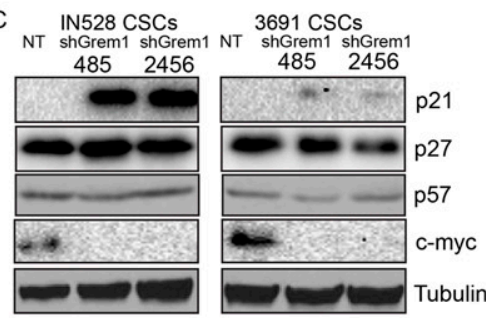

B

Role of $\mathrm{CHK}$ proteins in Cell Cycle Checkpoint Control



E

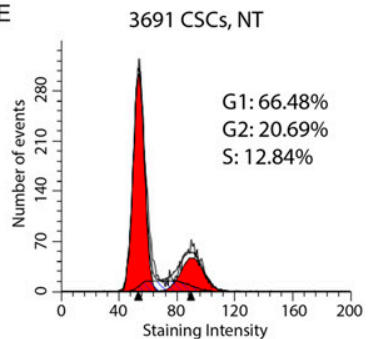

3691 CSCs, shGrem1_485

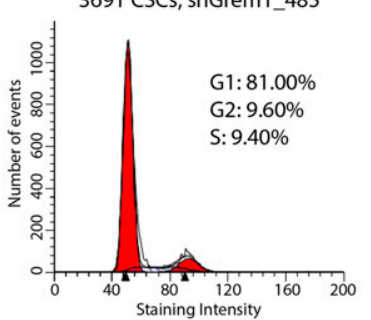

IN528 CSCs 3691 CSCs

సั.

ATRX

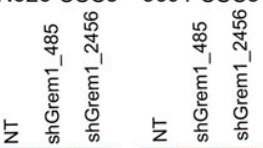

BAX

BIRC5

CCL2

CCNA2

CCNB1

DC25A

CDK1

CHEK1

CIT

FANCG

KIAA0101

KIF2C

MAD2L1

MCM4

MYC

ORC1

PCNA

PRC1

TERT

TOP2A

TP53

TP5313
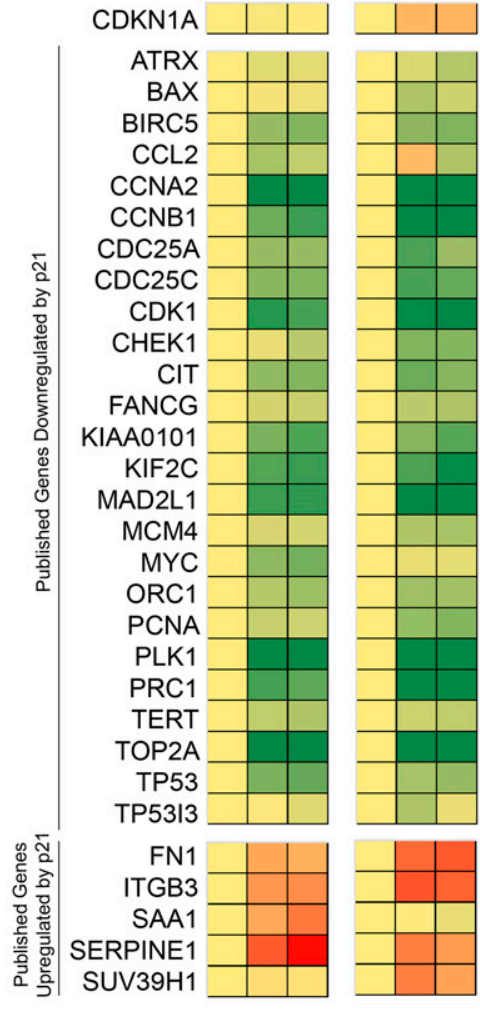

Most

Expressed

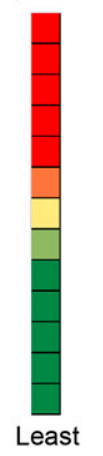

Expressed
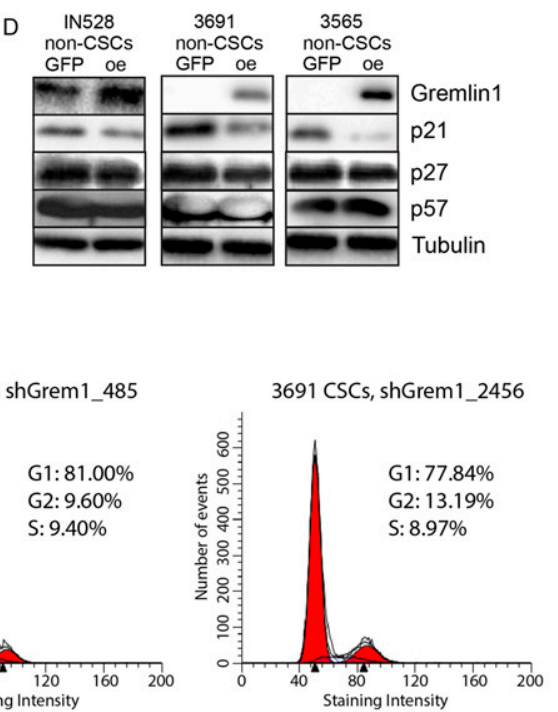

Figure 7. Gremlin1 promotes cell cycle progression in CSCs via p21. (A) Ingenuity pathway analysis of pathways up-regulated by Gremlin1 shRNA-derived gene expression data. (B) Heat map of gene expression changes following Gremlin 1 shRNA knockdown in genes previously characterized in the literature as up-regulated or down-regulated by p21; red is higher expression, and green is lower expression. $(C)$ Western blot of Gremlin1 knockdown in two CSC models for p21, p27, p57, c-Myc, and Gremlin1. $(D)$ Western blot of Gremlin1 overexpression in three CSC models for Gremlin1, p21, p27, and p57. (E) Cell cycle analysis following Gremlin1 shRNA knockdown in 3691 CSCs.

tumor recurrence following treatment (Bao et al. 2006a; Chen et al. 2012b). Many studies consider CSCs in isolation, but an essential aspect of the claims of a CSC identity requires that the original tumor contains a hierarchy and that the non-CSCs are derived from the CSCs. While it is clear that CSCs themselves contribute to tumor growth, 
there is increasing evidence that differentiated progeny promote tumor growth by forming a supportive niche for CSCs. For instance, non-CSCs support the tumor vasculature (Cheng et al. 2013), secrete extracellular matrix components (Lathia et al. 2012), and provide survival signals back to enhance CSC maintenance (Wang et al. 2009). This suggests that within a given tumor, there is a balance of differentiation and self-renewal to continuously generate differentiated progeny while maintaining the CSC population. Disrupting the balance between these forces may represent a potential target for tumor therapy.

BMP signaling is instructive about the mechanisms for maintenance of the tumor hierarchy. BMPs are key ligands that cause differentiation in CSCs, with a corresponding decrease in proliferation (Piccirillo et al. 2006). Despite this apparent negative effect on CSCs, endogenous BMPs, particularly BMP2, are secreted at high levels within bulk tumors compared with normal brain tissue (Liu et al. 2009; Zhang et al. 2009). While this seems paradoxical, these observations suggest that BMPs might be drivers of differentiation in the context of a balanced tumor hierarchy. Therefore, our studies have focused on the potential of a parallel driver of self-renewal to prevent the differentiation that would be caused by high endogenous BMP signaling.

BMP antagonists are expressed as counterbalances to modulate endogenous BMPs in both development and cancer. For instance, controlled secretion of BMPs and corresponding antagonists dictate embryonic patterning during gastrulation (Kishigami and Mishina 2005) and trigger termination of limb development (Verheyden and Sun 2008). In basal cell carcinoma, Gremlin1 and Follistatin are secreted by cancer-associated fibroblasts to inhibit BMPmediated decreases in cell proliferation (Sneddon et al. 2006). In melanoma, coordinated Noggin up-regulation protects melanoma cells from BMP-mediated growth inhibition (Hsu et al. 2008). Furthermore, the BMP inhibitor Coco is secreted to generate a permissive niche for lung metastases of breast cancer cells (Gao et al. 2012). These studies and others highlight the potential importance of BMP antagonism in general tumor biology.

Here, we found that the BMP inhibitor Gremlin1 is secreted in a CSC-specific manner to promote CSC maintenance, supporting the following model: First, BMPs are secreted to induce CSC differentiation and generate differentiated progeny important for tumor growth. Second, Gremlinl is secreted specifically by CSCs to shield CSCs in a BMP-rich environment. Hence, by modulating the levels of a driver of differentiation and a corresponding antagonist, gliomas are able to balance the levels of CSCs and differentiated progeny and thereby maintain the tumor hierarchy.

We also found a differential expression of Noggin expression in CSCs compared with nonstem glioma cells. However, Noggin expression levels were significantly lower than Gremlin1, and shRNA knockdown of Noggin did not alter CSC proliferation (data not shown). Furthermore, if Noggin and Gremlin1 played a similar role, we would expect Gremlin1 knockdown to have less of an effect due to compensatory Noggin secretion. Therefore, while there might be some level of compensatory Noggin secretion in CSCs, Gremlin1 still appears to be the primary antagonist responsible for hierarchy maintenance. Also, Gremlin1 treatments did not significantly influence CSC biology in the absence of exogenous BMP treatments. We suspect that the lack of an effect was simply due to the fact that CSCs are already producing substantial amounts of Gremlin1.

In this study, we also describe a link between Gremlin1 and the CKI p21. This is contrary to previous work in which Gremlin1 promoted p21 transcription in medulloblastoma (Chen et al. 2002). However, here, Gremlin1 does not affect $\mathrm{p} 21 \mathrm{mRNA}$ levels and rather decreases p21 protein levels. In NSCs, which are a relatively quiescent population, $\mathrm{p} 21$ promotes self-renewal through a number of different mechanisms, including the feedback inhibition of BMP2 (Marques-Torrejon et al. 2013; Porlan et al. 2013). Unlike NSCs, CSC self-renewal is linked to p21 inhibition and cell cycle progression (Bao et al. 2008; Wang et al. 2008). Furthermore, p21 has been established as a downstream effector of BMPs in a number of cancers. Therefore, Gremlin 1 inhibition of p21 in CSCs provides a key mechanism for Gremlin1's promotion of CSC selfrenewal and prevention of differentiation.

Finally, in addition to uncovering the novel role of Gremlin1 in maintaining hierarchies, this study is informative for BMP-based glioblastoma therapies. BMPbased therapies are designed to overwhelm tumors with differentiation signals, thereby collapsing the hierarchy and converting the entire tumor into a more differentiated tumor mass. However, this study raises the possibility that a patient's CSCs might tune their levels of secreted Gremlin1 in response to BMP-based targeted therapies, simply compensating for the perturbation in BMP levels by increased antagonist secretion. Furthermore, our overexpression studies suggest that Gremlin1 overexpression in non-CSCs antagonizes BMP signaling in these populations as well and promotes a more stemlike phenotype. This suggests that in the context of a BMP-based therapy, compensatory Gremlin1 secretion might revert partially differentiated populations back into CSCs. This complication should be taken into account as BMPs are considered as differentiation cancer therapies. To bypass this complication, one alternative would be to engineer a BMP variant that does not bind to Gremlin1 (Tate et al. 2012). If the BMP variant is refractory to Gremlin1 inhibition, it can be used to induce differentiation in CSCs without the worry of compensatory Gremlin 1 secretion.

Another avenue for therapy would be to explore combined therapies. As demonstrated by the use of antibodies to target secreted vascular endothelial growth factor (VEGF) (Khasraw et al. 2012), antibodies may be designed to target Gremlin1 as well. Antibodies against Gremlin1 can then be packaged with BMP therapies, thereby pushing differentiation in CSCs while at the same time destroying their protective mechanisms to resist differentiation. This would then enhance the effectiveness of BMP-based therapies. Our study suggests that such a combined therapy could be used to differentiate CSCs for therapeutic benefit. 


\section{Materials and methods}

Isolation and tissue culture of glioma CSCs and matched nonstem glioma cells

As described previously (Bao et al. 2006a,b; Cheng et al. 2011b; Eyler et al. 2011), cell cultures enriched for or depleted of CSCs were derived from primary patient brain tumor specimens or specimens passaged for seven or fewer passages as xenografts in immunocompromised mice. Tumor specimens were acutely dissociated using a papain-based dissociation kit (Worthington Biochemical) following the manufacturer's protocol. Following dissociation, cells were cultured for at least $6 \mathrm{~h}$ in Neurobasal medium supplemented with B27 without vitamin A (Gibco), L-glutamine, sodium pyruvate (Invitrogen), and $10 \mathrm{ng} / \mathrm{mL}$ each epidermal growth factor (EGF; R\&D Systems) and basic fibroblast growth factor (bFGF; R\&D Systems) for surface antigen recovery. After this brief incubation, CD133 antibody-conjugated magnetic beads (Miltenyi Biotec) or allophycocyanin-coated CD133 antibody (Millipore) were used to label the bulk tumor population. After $1 \mathrm{~h}$ of antibody labeling on ice, magnetic columns or flow cytometry were then used to segregate $\mathrm{CD} 133^{+}$ and $\mathrm{CD} 133^{-}$populations. Functional CSC assays were performed immediately after CD133 sorting by differential expression of stem cell markers, in vitro limiting dilution assays, and tumor formation assays. Cultures enriched for CSCs had increased stem cell marker expression and increased abilities for self-renewal and tumor initiation (Supplemental Fig. S2).

All differential RNA and protein expression data were collected from cell populations lysed immediately following magnetic or flow cytometric sorting. For treatment and knockdown experiments that necessitated extended cell culture, CSCs were cultured in supplemented Neurobasal medium, and non-CSCs were cultured in DMEM with $10 \%$ FBS briefly to maintain viability after sorting. Media for both CSCs and non-CSCs were switched to Neurobasal medium without EGF and FGF prior to performing any treatment, knockdown, or overexpression experiments.

\section{Lentiviral-mediated overexpression and knockdown}

An HIV-based plasmid with the Gremlin1 cDNA sequence driven by the CMV promoter (Genecopoiea) and a GFP control were used for Gremlin1 overexpression experiments. An FIVbased plasmid with shRNA clones (Genecopoiea) targeting Gremlin1 (shGrem1_485 target sequence, 5'-ACAGTCGCAC CATCATCAA-3'; shGrem1_2456 target sequence, 5' -GCAACTC GAGAAGCTGTTT-3') and a matched nontargeting control shRNA sequence that is not expressed in the human transcriptome (NT) were used for Gremlin1 knockdown experiments. Plasmids were cotransfected with packaging vectors psPAX2 and pCI-VSVG (Addgene) into 293FT cells using Lipofectamine 2000 (Invitrogen) or a calcium phosphate transfection method to produce virus. Cells were infected at the time of plating. Knockdown and overexpression were confirmed using Western blot.

\section{Immunofluorescent staining}

Cultured cells or $10-\mu \mathrm{m}$-thick slices of human or xenografted brain tissue were fixed in $4 \%$ formaldehyde and stained using the following antibodies: rabbit anti-Gremlin1 (Santa Cruz Biotechnology), goat anti-Sox2 (Santa Cruz Biotechnology), goat antiOlig2 (R\&D Systems), mouse anti-CD31 (DAKO), rat anti-CD31 (BD), mouse anti-Nestin (BD), mouse anti-CD133 (Miltenyi Biotec), rat anti-GFAP (Invitrogen), mouse anti-NG2 (Millipore), mouse ani-Map2 (Sigma), mouse anti-Tuj1 (Covance), mouse
anti-Sox2 (R\&D Systems), and mouse anti-O4 and rat anti-PLP (generous gifts from the laboratory of Dr. Paul Tesar, Case Western University). Primary antibodies were incubated for $16 \mathrm{~h}$ at $4^{\circ} \mathrm{C}$, followed by detection by the following secondary antibodies: Alexa 488 goat anti-rabbit or Alexa 488 goat anti-rat (Invitrogen), Alexa 568 goat anti-mouse, Alexa 568 goat antirabbit or Alexa 568 donkey anti-goat (Invitrogen), and Alexa 633 goat anti-rat (Invitrogen). Nuclei were stained using DAPI, and slides were mounted using Fluoromount (Calbiochem). Images were taken using a Leica DM4000 upright microscope.

\section{Microarray and microarray analysis}

Microarray hybridization and processing were performed at the Case Western Reserve University Genomics Sequencing Core according to the manufacturer's protocol using the GeneTitan multichannel instrument (Affymetrix). Biotinylated cDNA fragments were generated from $500 \mathrm{ng}$ of total RNA, and $180 \mathrm{ng}$ of cDNA was hybridized onto the HuGene 2.1 PEG array (Affymetrix). The HuGene 2.1 array covers $>30,000$ coding transcripts and 11,000 long intergenic noncoding transcripts.

Raw intensity values were normalized by robust multiarray average (RMA) analysis as previously described (Irizarry et al. 2003) using the Bioconductor oligo R package (Carvalho and Irizarry 2010). Using the raw gene expression values, fold changes for each gene were calculated between each pair of nontargeting and shRNA conditions. The fold changes were analyzed using Ingenuity pathway analysis (IPA; Ingenuity Systems) with the threshold of a more than twofold expression difference. The array data have been deposited into Gene Expression Omnibus (accession no. GSE52846).

\section{In vitro limiting dilution assay}

For the in vitro limiting dilution assay, CSCs were plated at one, five, 10, 20, 40, and 80 cells per well into a 96-well plate via flow cytometry. Ten days after plating, the number of neurospheres found in each well was quantified by manual counting. Extreme limiting dilution assay analyses (ELDAs) were performed on the data as previously described (Hu and Smyth 2009).

\section{In vivo tumor initiation assay}

All animal procedures were performed in accordance with Cleveland Clinic Institutional Animal Care and Use Committee-approved protocols. Animals were housed in a temperaturecontrolled vivarium with a 14-h light, 10 -h dark cycle at no more than five animals per cage. Bulk tumor populations $(10,000$ cells per mouse), nonstem glioma cell-enriched populations $(50,000$ cells per mouse), or CSCs (10,000 cells per mouse) were injected intracranially into a NOD-SCID immunocompromised mouse model. Mice were monitored over time for the development of neurological signs, such as lethargy, seizures, and/or ataxia, upon which their brains were removed. For immunofluorescent staining, anesthetized mice were perfused with PBS and 4\% paraformaldehyde (PFA) prior to removal of their brains. Their brains were then fixed in $4 \%$ PFA for $24-48 \mathrm{~h}$, sunk in $30 \%$ sucrose, cryopreserved in OCT, and sectioned for staining. For H\&E staining, brains were removed without perfusion, fixed in $4 \%$ PFA, paraffin-embedded, sectioned, and stained. Immunohistochemistry staining for p53 was performed on paraffin-embedded brains using mouse anti-p53 (Ventana).

\section{Acknowledgments}

We thank the Cleveland Clinic Flow Cytometry and Imaging Cores, Case Western Genomics Sequencing Core, and the viral laboratory 
of Professor Eric J. Arts for assistance with technical aspects of this project. In addition, we thank the laboratory of Professor Ichiro Nakano for providing specimens IN528 and IN1123 for our studies. Furthermore, we thank Dr. Shideng Bao and his laboratory for discussions and assistance. Finally, we thank our funding sources: National Institutes of Health grants CA154130 and CA1 129958 to J.N.R, TR000441 and CA165892 to K.Y., and CA151522 to A.B.H.; the Research Programs Committees of Cleveland Clinic (J.N.R); the University of Zurich (Forschungskredit) (I.T.); and the James S. McDonnell Foundation (J.N.R).

\section{References}

Abbas T, Dutta A. 2009. p21 in cancer: intricate networks and multiple activities. Nat Rev Cancer 9: 400-414.

Aboody KS, Brown A, Rainov NG, Bower KA, Liu S, Yang W, Small JE, Herrlinger U, Ourednik V, Black PM, et al. 2000. Neural stem cells display extensive tropism for pathology in adult brain: evidence from intracranial gliomas. Proc Natl Acad Sci 97: 12846-12851.

Ades L, Guerci A, Raffoux E, Sanz M, Chevallier P, Lapusan S, Recher C, Thomas X, Rayon C, Castaigne S, et al. 2010. Very long-term outcome of acute promyelocytic leukemia after treatment with all-trans retinoic acid and chemotherapy: the European APL Group experience. Blood 115: 1690-1696.

Anido J, Saez-Borderias A, Gonzalez-Junca A, Rodon L, Folch G, Carmona MA, Prieto-Sanchez RM, Barba I, Martinez-Saez E, Prudkin L, et al. 2010. TGF- $\beta$ receptor inhibitors target the CD44(high)/Id1(high) glioma-initiating cell population in human glioblastoma. Cancer Cell 18: 655-668.

Bao S, Wu Q, McLendon RE, Hao Y, Shi Q, Hjelmeland AB, Dewhirst MW, Bigner DD, Rich JN. 2006a. Glioma stem cells promote radioresistance by preferential activation of the DNA damage response. Nature 444: 756-760.

Bao S, Wu Q, Sathornsumetee S, Hao Y, Li Z, Hjelmeland AB, Shi Q, McLendon RE, Bigner DD, Rich JN. 2006b. Stem celllike glioma cells promote tumor angiogenesis through vascular endothelial growth factor. Cancer Res 66: 78437848.

Bao S, Wu Q, Li Z, Sathornsumetee S, Wang H, McLendon RE, Hjelmeland AB, Rich JN. 2008. Targeting cancer stem cells through L1CAM suppresses glioma growth. Cancer Res 68: 6043-6048.

Beck SE, Jung BH, Del Rosario E, Gomez J, Carethers JM. 2007. BMP-induced growth suppression in colon cancer cells is mediated by p21WAF1 stabilization and modulated by RAS/ ERK. Cell Signal 19: 1465-1472.

Besson A, Dowdy SF, Roberts JM. 2008. CDK inhibitors: cell cycle regulators and beyond. Dev Cell 14: 159-169.

Binda E, Visioli A, Giani F, Lamorte G, Copetti M, Pitter KL, Huse JT, Cajola L, Zanetti N, DiMeco F, et al. 2012. The EphA2 receptor drives self-renewal and tumorigenicity in stem-like tumor-propagating cells from human glioblastomas. Cancer Cell 22: 765-780.

Brubaker KD, Corey E, Brown LG, Vessella RL. 2004. Bone morphogenetic protein signaling in prostate cancer cell lines. J Cell Biochem 91: 151-160.

Calabrese C, Poppleton H, Kocak M, Hogg TL, Fuller C, Hamner B, Oh EY, Gaber MW, Finklestein D, Allen M, et al. 2007. A perivascular niche for brain tumor stem cells. Cancer Cell 11: 69-82.

The Cancer Genome Atlas. 2008. Comprehensive genomic characterization defines human glioblastoma genes and core pathways. Nature 455: 1061-1068.

Carvalho BS, Irizarry RA. 2010. A framework for oligonucleotide microarray preprocessing. Bioinformatics 26: 2363-2367.
Chen B, Athanasiou M, Gu Q, Blair DG. 2002. Drm/Gremlin transcriptionally activates p21(Cip1) via a novel mechanism and inhibits neoplastic transformation. Biochem Biophys Res Commun 295: 1135-1141.

Chen A, Wang D, Liu X, He S, Yu Z, Wang J. 2012a. Inhibitory effect of BMP-2 on the proliferation of breast cancer cells. Mol Med Rep 6: 615-620.

Chen J, Li Y, Yu TS, McKay RM, Burns DK, Kernie SG, Parada LF. 2012b. A restricted cell population propagates glioblastoma growth after chemotherapy. Nature 488: 522-526.

Cheng L, Wu Q, Guryanova OA, Huang Z, Huang Q, Rich JN, Bao S. 2011a. Elevated invasive potential of glioblastoma stem cells. Biochem Biophys Res Commun 406: 643-648.

Cheng L, Wu Q, Huang Z, Guryanova OA, Huang Q, Shou W, Rich JN, Bao S. 2011b. L1CAM regulates DNA damage checkpoint response of glioblastoma stem cells through NBS1. EMBO I 30: 800-813.

Cheng L, Huang Z, Zhou W, Wu Q, Donnola S, Liu JK, Fang X, Sloan AE, Mao Y, Lathia JD, et al. 2013. Glioblastoma stem cells generate vascular pericytes to support vessel function and tumor growth. Cell 153: 139-152.

Chirasani SR, Sternjak A, Wend P, Momma S, Campos B, Herrmann IM, Graf D, Mitsiadis T, Herold-Mende C, Besser D, et al. 2010. Bone morphogenetic protein-7 release from endogenous neural precursor cells suppresses the tumourigenicity of stem-like glioblastoma cells. Brain 133: 1961-1972.

Day BW, Stringer BW, Al-Ejeh F, Ting MJ, Wilson J, Ensbey KS, Jamieson PR, Bruce ZC, Lim YC, Offenhauser C, et al. 2013. EphA3 maintains tumorigenicity and is a therapeutic target in glioblastoma multiforme. Cancer Cell 23: 238-248.

Eichhorn PJ, Rodon L, Gonzalez-Junca A, Dirac A, Gili M, Martinez-Saez E, Aura C, Barba I, Peg V, Prat A, et al. 2012. USP15 stabilizes TGF- $\beta$ receptor I and promotes oncogenesis through the activation of TGF- $\beta$ signaling in glioblastoma. Nat Med 18: 429-435.

Eyler CE, Wu Q, Yan K, Macswords JM, Chandler-Militello D, Misuraca KL, Lathia JD, Forrester MT, Lee J, Stamler JS, et al. 2011. Glioma stem cell proliferation and tumor growth are promoted by nitric oxide synthase-2. Cell 146: 53-66.

Franzen A, Heldin NE. 2001. BMP-7-induced cell cycle arrest of anaplastic thyroid carcinoma cells via p21(CIP1) and p27(KIP1). Biochem Biophys Res Commun 285: 773-781.

Friday BB, Anderson SK, Buckner J, Yu C, Giannini C, Geoffroy F, Schwerkoske J, Mazurczak M, Gross H, Pajon E, et al. 2012. Phase II trial of vorinostat in combination with bortezomib in recurrent glioblastoma: a north central cancer treatment group study. Neuro-oncol 14: 215-221.

Gallo M, Ho J, Coutinho FJ, Vanner R, Lee L, Head R, Ling EK, Clarke ID, Dirks PB. 2013. A tumorigenic MLL-homeobox network in human glioblastoma stem cells. Cancer Res 73: 417-427.

Gao H, Chakraborty G, Lee-Lim AP, Mo Q, Decker M, Vonica A, Shen R, Brogi E, Brivanlou AH, Giancotti FG. 2012. The BMP inhibitor Coco reactivates breast cancer cells at lung metastatic sites. Cell 150: 764-779.

Gargiulo G, Cesaroni M, Serresi M, de Vries N, Hulsman D, Bruggeman SW, Lancini C, van Lohuizen M. 2013. In vivo RNAi screen for BMI1 targets identifies TGF- $\beta$ /BMP-ER stress pathways as key regulators of neural- and malignant glioma-stem cell homeostasis. Cancer Cell 23: 660-676.

Grauer O, Pascher C, Hartmann C, Zeman F, Weller M, Proescholdt M, Brawanski A, Pietsch T, Wick W, Bogdahn $\mathrm{U}$, et al. 2011. Temozolomide and 13-cis retinoic acid in patients with anaplastic gliomas: a prospective single-arm monocentric phase-II study (RNOP-05). I Neurooncol 104: 801-809. 
Groppe J, Greenwald J, Wiater E, Rodriguez-Leon J, Economides AN, Kwiatkowski W, Affolter M, Vale WW, Belmonte JC, Choe S. 2002. Structural basis of BMP signalling inhibition by the cystine knot protein Noggin. Nature 420: 636642.

Gu C, Banasavadi-Siddegowda YK, Joshi K, Nakamura Y, Kurt H, Gupta S, Nakano I. 2013. Tumor-specific activation of the C-JUN/MELK pathway regulates glioma stem cell growth in a p53-dependent manner. Stem Cells 31: 870-881.

Hsu MY, Rovinsky SA, Lai CY, Qasem S, Liu X, How J, Engelhardt JF, Murphy GF. 2008. Aggressive melanoma cells escape from BMP7-mediated autocrine growth inhibition through coordinated Noggin upregulation. Lab Invest 88: 842-855.

Hu Y, Smyth GK. 2009. ELDA: extreme limiting dilution analysis for comparing depleted and enriched populations in stem cell and other assays. J Immunol Methods 347: 7078.

Ikushima $\mathrm{H}$, Todo $\mathrm{T}$, Ino $\mathrm{Y}$, Takahashi $\mathrm{M}$, Miyazawa $\mathrm{K}$, Miyazono K. 2009. Autocrine TGF- $\beta$ signaling maintains tumorigenicity of glioma-initiating cells through Sry-related HMG-box factors. Cell Stem Cell 5: 504-514.

Irizarry RA, Hobbs B, Collin F, Beazer-Barclay YD, Antonellis KJ, Scherf U, Speed TP. 2003. Exploration, normalization, and summaries of high density oligonucleotide array probe level data. Biostatistics 4: 249-264.

Joshi K, Banasavadi-Siddegowda Y, Mo X, Kim SH, Mao P, Kig C, Nardini D, Sobol RW, Chow LM, Kornblum HI, et al. 2013. MELK-dependent FOXM1 phosphorylation is essential for proliferation of glioma stem cells. Stem Cells 31: 1051-1063.

Khasraw M, Simeonovic M, Grommes C. 2012. Bevacizumab for the treatment of high-grade glioma. Expert Opin Biol Ther 12: 1101-1111.

Kim M, Yoon S, Lee S, Ha SA, Kim HK, Kim JW, Chung J. 2012. Gremlin-1 induces BMP-independent tumor cell proliferation, migration, and invasion. PLOS ONE 7: e35100.

Kishigami S, Mishina Y. 2005. BMP signaling and early embryonic patterning. Cytokine Growth Factor Rev 16: 265-278.

Lathia JD, Li M, Hall PE, Gallagher J, Hale JS, Wu Q, Venere M, Levy E, Rani MR, Huang P, et al. 2012. Laminin $\alpha 2$ enables glioblastoma stem cell growth. Ann Neurol 72: 766-778.

Lee J, Son MJ, Woolard K, Donin NM, Li A, Cheng CH, Kotliarova S, Kotliarov Y, Walling J, Ahn S, et al. 2008. Epigenetic-mediated dysfunction of the bone morphogenetic protein pathway inhibits differentiation of glioblastomainitiating cells. Cancer Cell 13: 69-80.

Lesniak MS. 2006. Targeted therapy for malignant glioma: neural stem cells. Expert Rev Neurother 6: 1-3.

Li Z, Wang H, Eyler CE, Hjelmeland AB, Rich JN. 2009. Turning cancer stem cells inside out: an exploration of glioma stem cell signaling pathways. I Biol Chem 284: 16705-16709.

Liu G, Yuan X, Zeng Z, Tunici P, Ng H, Abdulkadir IR, Lu L, Irvin D, Black KL, Yu JS. 2006. Analysis of gene expression and chemoresistance of $\mathrm{CD}_{133^{+}}$cancer stem cells in glioblastoma. Mol Cancer 5: 67.

Liu C, Tian G, Tu Y, Fu J, Lan C, Wu N. 2009. Expression pattern and clinical prognostic relevance of bone morphogenetic protein-2 in human gliomas. Ipn J Clin Oncol 39: 625-631.

Lombardo Y, Scopelliti A, Cammareri P, Todaro M, Iovino F, Ricci-Vitiani L, Gulotta G, Dieli F, de Maria R, Stassi G. 2011. Bone morphogenetic protein 4 induces differentiation of colorectal cancer stem cells and increases their response to chemotherapy in mice. Gastroenterology 140: 297-309.

Marques-Torrejon MA, Porlan E, Banito A, Gomez-Ibarlucea E, Lopez-Contreras AJ, Fernandez-Capetillo O, Vidal A, Gil J, Torres J, Farinas I. 2013. Cyclin-dependent kinase inhibitor p21 controls adult neural stem cell expansion by regulating Sox2 gene expression. Cell Stem Cell 12: 88-100.

Miyazaki H, Watabe T, Kitamura T, Miyazono K. 2004. BMP signals inhibit proliferation and in vivo tumor growth of androgen-insensitive prostate carcinoma cells. Oncogene 23: 9326-9335.

Mulvihill MS, Kwon YW, Lee S, Fang LT, Choi H, Ray R, Kang HC, Mao JH, Jablons D, Kim IJ. 2012. Gremlin is overexpressed in lung adenocarcinoma and increases cell growth and proliferation in normal lung cells. PLOS ONE 7: e42264.

Namkoong H, Shin SM, Kim HK, Ha SA, Cho GW, Hur SY, Kim TE, Kim JW. 2006. The bone morphogenetic protein antagonist gremlin 1 is overexpressed in human cancers and interacts with YWHAH protein. BMC Cancer 6: 74.

Penuelas S, Anido J, Prieto-Sanchez RM, Folch G, Barba I, Cuartas I, Garcia-Dorado D, Poca MA, Sahuquillo J, Baselga $\mathrm{J}$, et al. 2009. TGF- $\beta$ increases glioma-initiating cell selfrenewal through the induction of LIF in human glioblastoma. Cancer Cell 15: 315-327.

Piccirillo SG, Reynolds BA, Zanetti N, Lamorte G, Binda E, Broggi G, Brem H, Olivi A, Dimeco F, Vescovi AL. 2006. Bone morphogenetic proteins inhibit the tumorigenic potential of human brain tumour-initiating cells. Nature 444: 761-765.

Porlan E, Morante-Redolat JM, Marques-Torrejon MA, AndreuAgullo C, Carneiro C, Gomez-Ibarlucea E, Soto A, Vidal A, Ferron SR, Farinas I. 2013. Transcriptional repression of Bmp2 by $21^{\text {Waf1/Cip1 }}$ links quiescence to neural stem cell maintenance. Nat Neurosci 16: 1567-1575.

Reya T, Morrison SJ, Clarke MF, Weissman IL. 2001. Stem cells, cancer, and cancer stem cells. Nature 414: 105-111.

Rheinbay E, Suva ML, Gillespie SM, Wakimoto H, Patel AP, Shahid M, Oksuz O, Rabkin SD, Martuza RL, Rivera MN, et al. 2013. An aberrant transcription factor network essential for wnt signaling and stem cell maintenance in glioblastoma. Cell Rep 3: 1567-1579.

Rider CC, Mulloy B. 2010. Bone morphogenetic protein and growth differentiation factor cytokine families and their protein antagonists. Biochem J 429: 1-12.

Sato $T$, van Es JH, Snippert HJ, Stange DE, Vries RG, van den Born M, Barker N, Shroyer NF, van de Wetering M, Clevers H. 2011. Paneth cells constitute the niche for Lgr5 stem cells in intestinal crypts. Nature 469: 415-418.

Secondini C, Wetterwald A, Schwaninger R, Thalmann GN, Cecchini MG. 2011. The role of the BMP signaling antagonist noggin in the development of prostate cancer osteolytic bone metastasis. PLOS ONE 6: e16078.

Sieber C, Kopf J, Hiepen C, Knaus P. 2009. Recent advances in BMP receptor signaling. Cytokine Growth Factor Rev 20: 343-355.

Singh SK, Hawkins C, Clarke ID, Squire JA, Bayani J, Hide T, Henkelman RM, Cusimano MD, Dirks PB. 2004. Identification of human brain tumour initiating cells. Nature 432: 396-401.

Sneddon JB, Zhen HH, Montgomery K, van de Rijn M, Tward $\mathrm{AD}$, West R, Gladstone H, Chang HY, Morganroth GS, Oro $\mathrm{AE}$, et al. 2006. Bone morphogenetic protein antagonist gremlin 1 is widely expressed by cancer-associated stromal cells and can promote tumor cell proliferation. Proc Nat1 Acad Sci 103: 14842-14847.

Tate CM, Pallini R, Ricci-Vitiani L, Dowless M, Shiyanova T, D'Alessandris GQ, Morgante L, Giannetti S, Larocca LM, di Martino S, et al. 2012. A BMP7 variant inhibits the tumorigenic potential of glioblastoma stem-like cells. Cell Death Differ 19: 1644-1654. 
Yan et al.

Tchaicha JH, Reyes SB, Shin J, Hossain MG, Lang FF, McCarty JH. 2011. Glioblastoma angiogenesis and tumor cell invasiveness are differentially regulated by $\beta 8$ integrin. Cancer Res 71: 6371-6381.

Varga AC, Wrana JL. 2005. The disparate role of BMP in stem cell biology. Oncogene 24: 5713-5721.

Verheyden JM, Sun X. 2008. An Fgf/Gremlin inhibitory feedback loop triggers termination of limb bud outgrowth. Nature 454: 638-641.

Vigneron A, Cherier J, Barre B, Gamelin E, Coqueret O. 2006. The cell cycle inhibitor p2lwafl binds to the myc and cdc25A promoters upon DNA damage and induces transcriptional repression. J Biol Chem 281: 34742-34750.

Walsh DW, Godson C, Brazil DP, Martin F. 2010. Extracellular BMP-antagonist regulation in development and disease: tied up in knots. Trends Cell Biol 20: 244-256.

Wang J, Wang $\mathrm{H}, \mathrm{Li} \mathrm{Z}$, Wu Q, Lathia JD, McLendon RE, Hjelmeland $A B$, Rich JN. 2008. c-Myc is required for maintenance of glioma cancer stem cells. PLOS ONE 3: e3769.

Wang H, Lathia JD, Wu Q, Wang J, Li Z, Heddleston JM, Eyler CE, Elderbroom J, Gallagher J, Schuschu J, et al. 2009. Targeting interleukin 6 signaling suppresses glioma stem cell survival and tumor growth. Stem Cells 27: 2393-2404.

Wang L, Park P, Zhang H, La Marca F, Claeson A, Valdivia J, Lin CY. 2011. BMP-2 inhibits the tumorigenicity of cancer stem cells in human osteosarcoma OS99-1 cell line. Cancer Biol Ther 11: 457-463.

Weller M, Cloughesy T, Perry JR, Wick W. 2013. Standards of care for treatment of recurrent glioblastoma-are we there yet? Neuro-oncol 15: 4-27.

Ye XZ, Xu SL, Xin YH, Yu SC, Ping YF, Chen L, Xiao HL, Wang B, Yi L, Wang QL, et al. 2012. Tumor-associated microglia/ macrophages enhance the invasion of glioma stem-like cells via TGF- $\beta 1$ signaling pathway. I Immunol 189: 444-453.

Yemelyanova A, Vang R, Kshirsagar M, Lu D, Marks MA, Shih Ie M, Kurman RJ. 2011. Immunohistochemical staining patterns of p53 can serve as a surrogate marker for TP53 mutations in ovarian carcinoma: an immunohistochemical and nucleotide sequencing analysis. Mod Pathol 24: 12481253.

Yi L, Xiao H, Xu M, Ye X, Hu J, Li F, Li M, Luo C, Yu S, Bian X, et al. 2011. Glioma-initiating cells: a predominant role in microglia/macrophages tropism to glioma. J Neuroimmunol 232: $75-82$.

Zhang X, Wu J, Li X, Fu L, Gao D, Bai H, Liu X. 2002. [Effects of recombinant human bone morphogenic protein-2 and hyaluronic acid on invasion of brain glioma in vivo]. Zhonghua Yi Xue Za Zhi (Taipei) 82: 90-93.

Zhang MY, Wu J, Gong X, Chen RK, Fang JS. 2009. [Clinical significance of BMP-2 protein and mRNA expression in human glioma]. Xibao Yu Fenzi Mianyixue Zazhi 25: 637639.

Zheng H, Ying H, Yan H, Kimmelman AC, Hiller DJ, Chen AJ, Perry SR, Tonon G, Chu GC, Ding Z, et al. 2008. p53 and Pten control neural and glioma stem/progenitor cell renewal and differentiation. Nature 455: 1129-1133. 


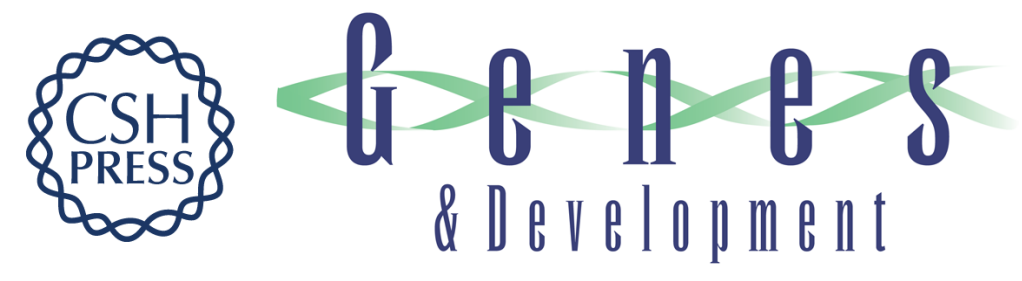

\section{Glioma cancer stem cells secrete Gremlin1 to promote their maintenance within the tumor hierarchy}

Kenneth Yan, Qiulian Wu, Diana H. Yan, et al.

Genes Dev. 2014, 28: originally published online May 1, 2014

Access the most recent version at doi:10.1101/gad.235515.113

\section{Supplemental http://genesdev.cshlp.org/content/suppl/2014/04/21/gad.235515.113.DC1 Material}

References This article cites 78 articles, 12 of which can be accessed free at: http://genesdev.cshlp.org/content/28/10/1085.full.html\#ref-list-1

Creative This article is distributed exclusively by Cold Spring Harbor Laboratory Press for the first Commons six months after the full-issue publication date (see

License http://genesdev.cshlp.org/site/misc/terms.xhtml). After six months, it is available under a Creative Commons License (Attribution-NonCommercial 4.0 International), as described at http://creativecommons.org/licenses/by-nc/4.0/.

Email Alerting Receive free email alerts when new articles cite this article - sign up in the box at the top Service right corner of the article or click here.



Focused on your science. 